\title{
Assessment of Autonomic Function in Patients with a Parkinsonian Syndrome
}

\author{
M. J. AMINOFF, C. S. WILCOX
}

British Medical fournal, 1971, 4, 80-84

\section{Summary}

The integrity of the autonomic nervous system was assessed in 11 Parkinsonian patients with symptoms suggestive of autonomic dysfunction. Three had the additional clinical features of the Shy-Drager variant of idiopathic orthostatic hypotension and were found to have a gross disturbance of vasomotor, sudomotor, pilomotor, and bladder function; assessment indicated that a lesion was present at sympathetic ganglionic level or beyond in two cases, though a more centrally placed lesion may well have been present also, as in the third case. In the remaining eight patients with paralysis agitans no unequivocal functional disturbance was found except in the bladder; nevertheless, the low resting blood pressure and the supersensitivity to intravenously infused L-noradrenaline in the three patients in whom it was tested is taken to imply defective regulation from higher centres, with a consequent reduction in impulse traffic at sympathetic nerve terminals. Such a concept is supported by experimental studies in animals and would account for the low renin and aldosterone secretion rates and reduced noradrenaline formation reported by others in patients with paralysis agitans.

\section{Introduction}

James Parkinson's (1817) original description of the disease which often bears his name includes constipation, drooling of saliva, and, as a late event, "the urine and faeces are passed involuntarily." Until recently clinicians have often neglected such autonomic symptoms or ascribed them to the anticholinergic drugs which these patients receive. Vegetative symptoms were found in $\mathbf{7 4} \%$ of Parkinsonian patients (Spiegel et al., 1969); some of these implied autonomic underactivity (constipation, impotence, and diminished sweating) and others overactivity (excessive sweating, salivation, and lachrymation, hypersecretion of nasal glands, oily skin, and diarrhoea). Abnormalities of bladder function are surprisingly common, occurring in $70 \%$ of patients (Porter et al., 1969). The blood pressure in such patients is usually lower than the mean for their age group, and there is a diminished ability to secrete renin (Barbeau et al., 1970), which may reflect reduced activity in the sympathetic nervous system. Such studies show how common and extensive is the autonomic disturbance in Parkinson's disease. The introduction of levodopa therapy has emphasized the need for more detailed information of autonomic function in this condition. Thus levodopa may alleviate the bladder disturbance and excessive lachrymation (Cotzias et al., 1969) while exacerbating the hypotension (Calne et al., 1970) and reducing renin secretion further (Barbeau et al., 1970).

Postmortem studies have shown morphological changes at many levels of the autonomic nervous system in Parkinsonian

Department of Neurological Studies, the Middlesex Hospital Medical School, London W1N 8AA

M. J. AMINOFF, B.SC., M.R.C.P., Registrar in Neurology

C. S. WILCOX, B.M., M.R.C.P., Lecturer patients. The hypothalamus (Lewy, 1923), the basal ganglia and reticular formation (Foix and Nicolesco, 1925), the dorsal nuclei of the vagus (Greenfield, 1955), the sympathetic ganglia (Jager and Bethlem, 1960), and the adrenal medulla (Jager, 1970) have all been implicated. Physiological studies designed to test the component parts of the autonomic nervous system are needed to determine which morphological lesions have functional significance. This study describes the application of such tests to a group of Parkinsonian patients who have symptoms suggestive of autonomic dysfunction.

\section{Methods}

Six men and five women, aged 51 to 68, with Parkinsonism were studied. There was no past history of encephalitic illness or of phenothiazine ingestion in any patient. Their symptoms and degree of incapacity (Yahr et al., 1968) are detailed in Table I, the abnormal neurological signs in Table II, and their antiParkinsonian therapy during the period of investigation is shown in Table III. The nature and purpose of the tests were fully explained to them and the tests were made only with their consent.

Routine investigations in all cases with normal results included a full blood count and sedimentation rate, blood urea and electrolytes, glucose tolerance test, blood Wassermann reaction, 8 a.m. plasma cortisol levels, midstream urine analysis, electrocardiogram, and plain radiographs of chest and skull. In all patients with objective evidence of autonomic dysfunction rectal biopsy provided no histological evidence of amyloidosis. The following tests of autonomic function were also performed.

Studies of Vasomotor Function.-Lying and standing blood pressure and pulse were recorded four times daily for each patient for a two-week period. In addition, the effect on blood pressure and pulse of postural variation effected passively on a tilt-table was

TABLE I-Symptoms

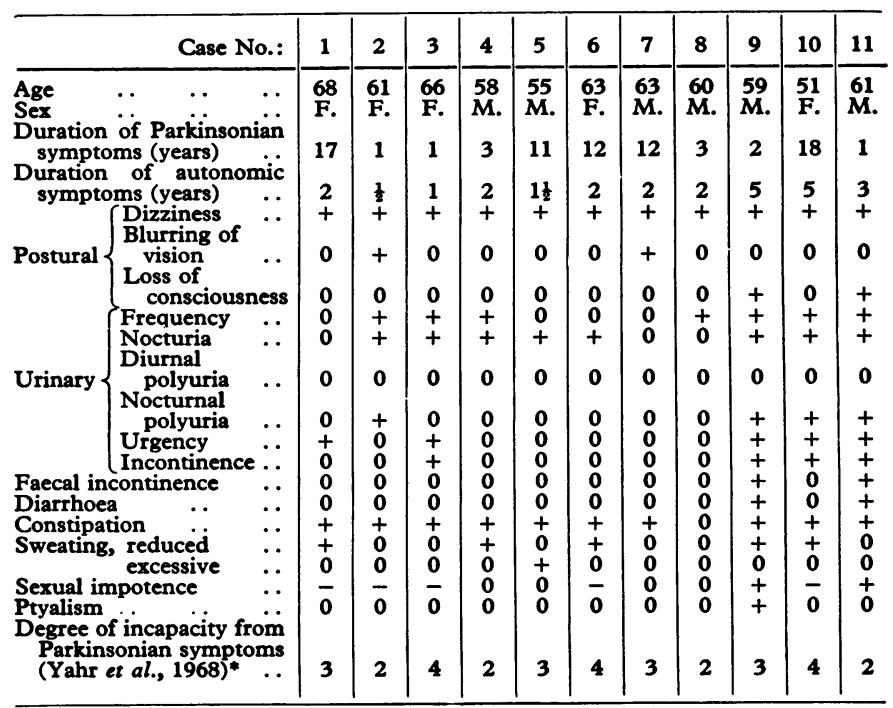

* Stage 1, mild unilateral symptoms. Stage 2, bilateral symptoms. Stage 3, moderate incapacity. Stage 4, significant akinesia and needing major assistance. Stage 5, complete invalidism. 
TABLE II-SignS

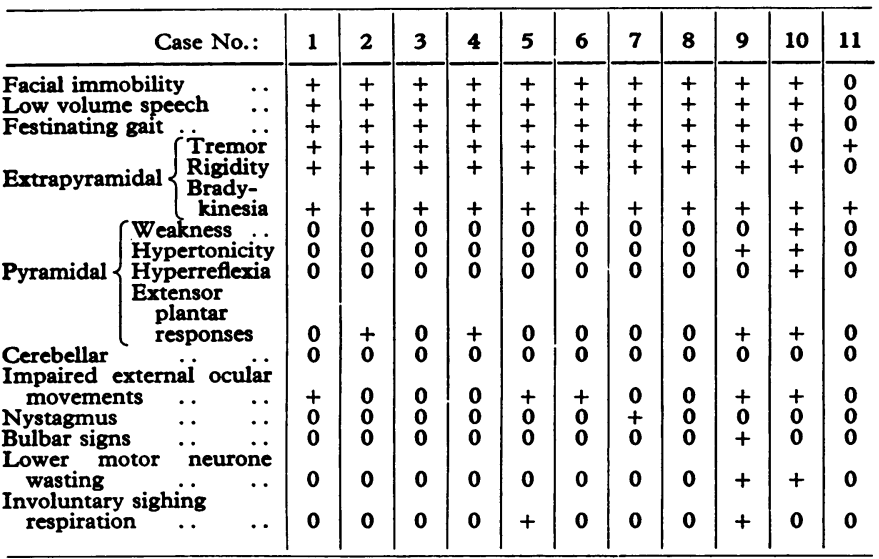

There was no sensory loss in any patient.

determined. With continuous blood pressure recordings through an indwelling brachial artery needle connected by a pressure transducer to a Devices recorder, patients blew a mercury co tn up to $40 \mathrm{~mm}$ with the glottis open and maintained it at this level until the maximum pulse pressure decrease had persisted for at least seven seconds. This is a well-recognized variation of the standard Valsalva manoeuvre (Sharpey-Schafer and Taylor, 1960). The responses to sudden loud noise or mental arithmetic were assessed while monitoring the blood pressure through the intraarterial needle. Vasomotor responses of patients to deep inspiration were recorded in the index fingers of both hands with a finger plethysmograph to assess blood flow rates. L-Noradrenaline acid tartrate in normal saline was infused intravenously for four-minute periods in increasing doses until a rise of $40 \mathrm{~mm} \mathrm{Hg}$ in systolic pressure, recorded with the sphygmomanometer, was obtained. Lobeline hydrochloride $(3 \mathrm{mg}$ ) was given by rapid intravenous injection and the response noted (Berliner, 1940).
Sudomotor Function.-Patients were warmed with a radiant heat cradle (800 watts) over the trunk for 20-60 minutes to raise the sublingual temperature by $1^{\circ} \mathrm{C}$; quinizarin powder (Guttmann, 1940) was used to detect sweating.

Pilomotor Function.-1\% acetylcholine $(0.1 \mathrm{ml})$ was injected intradermally into both forearms and thighs to produce local piloerection.

Parasympathetic Activity.-The effect of intravenous atrophine $(0.6 \mathrm{mg})$ on the heart rate of patients lying quietly was recorded. A standard insulin hypoglycaemia test was performed. Soluble insulin, $0.15 \mathrm{unit} / \mathrm{kg}$, was given intravenously following an overnight fast. Blood samples were taken at half-hourly intervals for two hours after the injection for estimation of blood sugar, and samples of gastric aspirate were withdrawn at similar intervals for determination of the free hydrogen ion concentration. In all patients reported here the blood sugar fell to $40 \mathrm{mg} / 100 \mathrm{ml}$ or below.

Bladder Function.-Micturating cinecystography with full pressure studies was undertaken on all patients.

\section{Results and Conclusions}

The results of our studies on vasomotor function in these patients are summarized in Table IV. Significant postural hypotension has been defined as a reduction in the systolic pressure by $30 \mathrm{~mm} \mathrm{Hg}$, or to $80 \mathrm{~mm} \mathrm{Hg}$ or less, on standing (McDowell, 1970). By these criteria, three of our patients (Cases 9, 10, and 11) are clearly distinguished from the remainder by the high frequency with which postural hypotension was recorded. Their vasomotor responses to passive changes in posture on a tilt-table are similarly distinctive in showing a percentage fall in mean pressure greater than the other patients.

In response to the Valsalva manoeuvre Cases 1-8 showed a baroreceptor reflex latency that averaged 6.9 seconds, while for Gross's (1970a) control subjects within an age range of 54-64 years the corresponding figure was $7 \cdot 1$ seconds. Furthermore, in the control subjects of Gross (1970b) the ratio of percentage increase in diastolic pressure after the forced expiration to

TABLE III-Anti-Parkinsonian Therapy while under Investigation

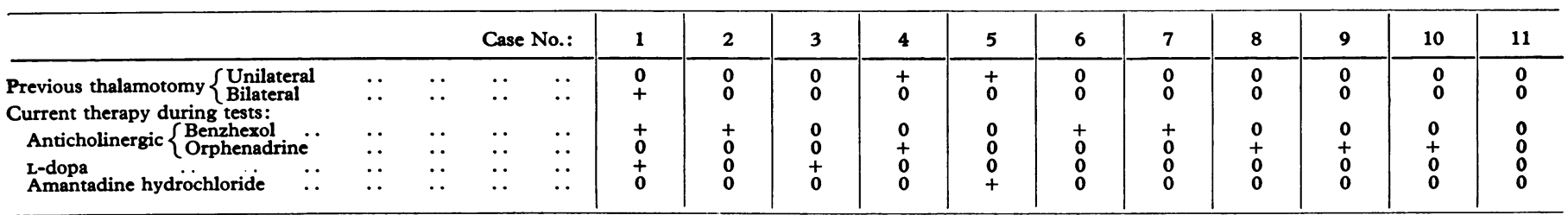

TABLE IV-Studies of Vasomotor Function

\begin{tabular}{|c|c|c|c|c|c|c|c|c|c|c|c|}
\hline Case No.: & 1 & 2 & 3 & 4 & 5 & 6 & 7 & 8 & 9 & 10 & 11 \\
\hline 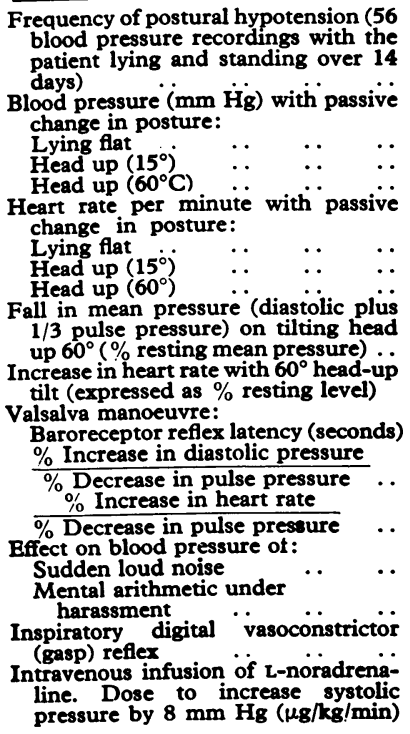 & $\begin{array}{c}\text { Pressor } \\
\text { Pressor } \\
\text { Intact } \\
\text { Not } \\
\text { performed }\end{array}$ & $\begin{array}{c}\text { No change } \\
\text { No change } \\
\text { Intact } \\
\text { Not } \\
\text { performed }\end{array}$ & $\begin{array}{c}\text { Pressor } \\
\text { No change } \\
\text { Intact } \\
\text { Not } \\
\text { performed }\end{array}$ & $\begin{array}{c}\text { No change } \\
\text { Pressor } \\
\text { Intact } \\
\text { Not } \\
\text { performed }\end{array}$ & $\begin{array}{l}84 \\
84 \\
87 \\
2 \\
4 \\
6.4 \\
0.36 \\
0.17\end{array}$ & $\begin{array}{l}78 \\
80 \\
80 \\
\\
0 \\
3 \\
5.8 \\
0.26 \\
0.28\end{array}$ & $\begin{array}{c}\text { No change } \\
\text { No change } \\
\text { Intact } \\
\text { Not } \\
\text { performed }\end{array}$ & $\begin{array}{c}62 \\
67 \\
95 \\
0 \\
53 \\
6.1 \\
0.86 \\
0.34\end{array}$ & $\begin{array}{c}120 / 70 \\
100 / 70 \\
60 / 40 \\
\\
68 \\
74 \\
92 \\
\\
47 \\
35 \\
\text { Infinite } \\
0 \\
0\end{array}$ & $\begin{array}{c}\text { Perform } \\
\text { No change } \\
\text { No change } \\
\text { Absent }\end{array}$ & $\begin{array}{c}11 \\
20 \\
\text { Infinite } \\
0 \\
0\end{array}$ \\
\hline
\end{tabular}


percentage decrease in pulse pressure during the forced expiration was 0.55; and the ratio of percentage increase in heart rate during the forced expiration to percentage decrease in pulse pressure during the forced expiration was $0 \cdot 25$. The corresponding figures for our patients were 0.64 and 0.35 respectively, showing clearly that there was no impairment of circulatory reflex activity in this group of patients. However, in Cases 9 and 11 circulatory reflex activity as assessed by this method was absent.

The inspiratory digital vasoconstrictor reflex is a spinal reflex (Gilliatt et al., 1948) with an unknown afferent pathway (Gilliatt, 1948), the efferent arc being that of the sympathetic outflow (Bolton et al., 1936). The loss of this reflex in Cases 9 and 10 strongly suggests a lesion at spinal segmental level of sympathetic pathways or their efferent connexions; such a lesion could in itself account for the postural hypotension, supersensitivity to infused noradrenaline, and the other evidence of grossly impaired circulatory control found in these two patients. The gasp reflex was reserved in all our other patients, including Case 11; the severe loss of circulatory control in this patient must therefore be due to a more proximal lesion, and clearly such a disturbance may also be present in Cases 9 and 10 , in addition to the lesion at or beyond segmental level.

The intravenous infusion of L-noradrenaline in six patients (Cases 5, 6, 8, 9, 10, and 11) produced a pressor response. Indeed, in all six the dose of L-noradrenaline required to produce a rise of $8 \mathrm{~mm} \mathrm{Hg}$ in systolic pressure was well below the dose range of $0.05-0.07 \mu \mathrm{g} / \mathrm{kg} / \mathrm{min}$ found by Goldberg $e t$ al. (1948) for normal subjects and confirmed by us; and Cases 9 , 10, and 11 showed a more pronounced supersensitivity than the other patients. The pressor dose in all our patients was also below the range found in a group of geratric subjects by Finnerty et al. (1959). This pressor response caused a prompt reduction in pulse rate in three patients (Cases 5, 8, and 11), two of whom showed a normal response to the Valsalva manœuvre. In Case 11 the bradycardia so induced implies that baroreceptor afferent fibres are functionally intact (Martin et al., 1968). The impaired response to the Valsalva manœuvre in this patient must therefore be attributed to a central suprasegmental lesion; this of interest since some authors have assumed that afferent baroreceptor fibres cannot be tested (Bannister et al., 1967).

The normal pressor response to startle or stress is not inconsistent with this, since the central pathways are not necessarily common to those mediating the baroreceptor reflexes, and both hormonal and nervous mechanisms are involved in this response (Barcroft et al., 1960). Atropine abolishes the bradycardia that accompanies the rise in pressure after the Valsalva manœuvre (Sharpey-Schafer, 1965) and noradrenaline infusion (Goldberg et al., 1948) which is therefore indicative of parasympathetic activity (Table V). However, absence of pressor-induced bradycardia may occur in the elderly and does not in itself provide evidence of a parasympathetic lesion (Sharpey-Schafer, 1965). In all patients the integrity of vagal pathways was shown by at least one of the four tests used (Table V).

Afferent fibres in the ninth and tenth cranial nerves were shown to be intact in all patients by the rapid intravenous injection of lobeline, which produced a reflex cough and hyperpnoea by stimulation of chemoreceptors (Berliner, 1940).

Studies of sudomotor function (Table VI) showed a patchy impairment of thermoregulatory sweating in six patients; this was most pronounced in Cases 3, 7, 9, and 10, all of whom showed total anhidrosis over the neck, trunk, and limbs. This possibly relates to the anticholinergic drugs that all these patients were receiving or to their age (Johnson et al., 1965); alternatively, there must be an interruption of thermoregulatory pathways either centrally or peripherally. In Cases 9 and 10 the additional loss of the pilomotor reflex is suggestive of a lesion at or beyond the sympathetic ganglia, irrespective of any more proximal disturbance, since this is an axonal reflex in functionally intact postganglionic sympathetic fibres (Coon and Rothman, 1941 ; Janowitz and Grossman, 1950; Barany and Cooper, 1956). If vasomotor fibres were also implicated in the lesion at this site it would account for the loss of the gasp reflex and the other vasomotor abnormalities in these two patients.

Bladder function, as assessed by cystometrogram and micturating cinecystography, was abnormal in 10 patients (Table VII).

TABLE VII-Bladder Function as Assessed by Cystometrogram and Micturating Cine-cystography

\begin{tabular}{|c|c|c|c|c|c|c|c|c|c|c|c|}
\hline Case No.: & 1 & 2 & 3 & 4 & 5 & 6 & 7 & 8 & 9 & 10 & 11 \\
\hline $\begin{array}{l}\text { Normal } \\
\text { Systolic (spastic) on filling } \\
\text { Unsustained detrusor con- } \\
\text { traction during empty- } \\
\text { ing } \\
\text { Flaccid }\end{array} \ldots$ & + & + & + & + & + & + & + & + & + & + & $\begin{array}{l}+ \\
+\end{array}$ \\
\hline
\end{tabular}

\section{Discussion}

During the study it became apparent that the patients could be divided into two distinct groups. In the first group (Cases 9, 10 , and 11) autonomic symptoms were prominent, preceding somatic neurological manifestations in two patients, and two showed both upper and lower motor neurone signs in addition to a conspicuous Parkinsonian syndrome.

\begin{tabular}{|c|c|c|c|c|c|c|c|c|c|c|c|}
\hline Case No.: & 1 & 2 & 3 & 4 & 5 & 6 & 7 & 8 & 9 & 10 & 11 \\
\hline 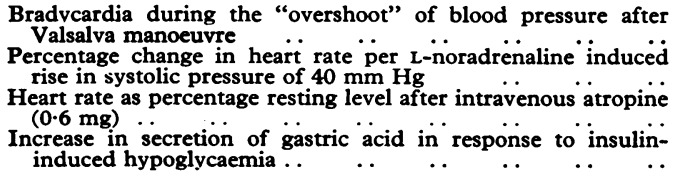 & 131 & 125 & + & $\begin{array}{c}117 \\
+\end{array}$ & $\begin{array}{c}+ \\
-9 \\
117\end{array}$ & $\begin{array}{c}0 \\
0 \\
126 \\
+\end{array}$ & 114 & $\begin{array}{c}+ \\
-13\end{array}$ & $\begin{array}{c}\text { NPR } \\
+3\end{array}$ & $\begin{array}{c}\text { NPR } \\
+6\end{array}$ & $\begin{array}{l}+ \\
-11 \\
115 \\
+\end{array}$ \\
\hline
\end{tabular}

NPR $=$ No pressor response.

TABLE VI-Sudomotor and Pilomotor Function

\begin{tabular}{|c|c|c|c|c|c|c|c|c|c|c|c|c|c|c|}
\hline & & & Case No.: & 1 & 2 & 3 & 4 & 5 & 6 & 7 & 8 & 9 & 10 & 11 \\
\hline $\begin{array}{l}\text { Thermoregulatory sweat test: } \\
\text { Sweat detected on }\left\{\begin{array}{l}\text { Brow } \\
\text { Limbs } \\
\text { Neck and trunk }\end{array}\right. \\
\text { Acetylcholine test (pilomotor reflex) }\end{array}$ & $\begin{array}{l}\because \\
\because \\
\because\end{array}$ & $\begin{array}{l}\because \\
\because \\
\therefore\end{array}$ & $\begin{array}{l}\because \\
\because \\
\because\end{array}$ & $\begin{array}{l}+ \\
+ \\
+ \\
+\end{array}$ & $\begin{array}{l}+ \\
0 \\
+ \\
+\end{array}$ & $\begin{array}{l}+ \\
0 \\
0 \\
+\end{array}$ & $\begin{array}{l}+ \\
0 \\
+ \\
+\end{array}$ & $\begin{array}{l}+ \\
+ \\
+\end{array}$ & $\begin{array}{l}+ \\
+ \\
+\end{array}$ & $\begin{array}{l}+ \\
0 \\
0 \\
+\end{array}$ & $\begin{array}{l}+ \\
+ \\
+\end{array}$ & $\begin{array}{l}+ \\
0 \\
0 \\
0\end{array}$ & $\begin{array}{l}+ \\
0 \\
0 \\
0\end{array}$ & $\begin{array}{l}+ \\
+ \\
+\end{array}$ \\
\hline
\end{tabular}


Investigations showed a considerable disturbance of vasomotor, sudomotor, pilomotor, and bladder function with evidence of a peripheral pilomotor lesion affecting postganglionic neurones and vasomotor lesions both centrally and peripherally. The lesion underlying the bladder disturbances cannot be clearly localized. This association of dysautonomia with a multisystem degenerative disorder of the motor nervous system is now referred to as the Shy-Drager variant of idiopathic orthostatic hypotension (Shy and Drager, 1960). While the dysautonomia has been ascribed to loss of preganglionic sympathetic neurones (Johnson et al., 1965), corresponding degeneration in the intermediolateral cell columns of the spinal cord found by some (Shy and Drager, 1960; Johnson et al., 1966; Schwarz, 1967; Graham and Oppenheimer, 1969) is not consistently seen (Martin et al., 1968; Hughes et al., 1970). However, others have concluded from physiological studies that the lesion is centrally placed (Stead and Ebert, 1941; Verel, 1951; Martin et al., 1968; Chokroverty et al., 1969).

Degenerative changes have also been reported in the autonomic ganglia (Shy and Drager, 1960; Schwarz, 1967; Hughes et al., 1970; Vanderhaeghen et al., 1970), and orthostatic hypotension related to a diminished formation or availability of the postganglionic neurotransmitter substance, noradrenaline (Luft and von Euler, 1953; Hickler et al., 1959a, 1959b; Goodall. et al., 1968). Such pathological and physiological variation precludes broad generalizations on the site of the lesion from observations in individual patients.

In the Shy-Drager syndrome somatic neurological signs may precede the dysautonomia (Thomas and Schirger, 1970) as in Case 10. A conspicuous Parkinsonian syndrome may then lead to an erroneous diagnosis of paralysis agitans.

In our second group of patients (Cases 1-8) automatic symptoms succeeded somatic, and examination showed the characteristic features of paralysis agitans. Two patients had bilateral extensor plantar responses, which were probably related in one (Case 2) to cervical spondylosis and in the other (Case 4) to previous thalamotomy. The nystagmus in Case 7 was an unexplained finding. Investigations in this group with paralysis agitans showed a resting blood pressure lower than that expected for this age and sex (Pickering, 1955), an increased sensitivity to infused L-noradrenaline, a patchy impairment of thermoregulatory sweating, and a disturbance of bladder function. In Cases 1 and 3 autonomic symptoms preceded the levodopa therapy they were receiving while under investigation, but the small fall in pressure on passive tilting in Case 1 and the slightly higher incidence of postural hypotension in Case 3 may have been related to this treatment.

Our results confirm those of Reid et al. (1971) that circulatory reflexes are intact in patients with paralysis agitans. The high incidence of bladder dysfunction is of interest, and agrees with that reported in paralysis agitans (Murnaghan, 1961; Porter et al., 1969). Precise localization of the underlying lesion is not possible, but thalamotomy may result in considerable improvement of bladder function. Furthermore, the instillation of water into the bladder during thalamotomy may evoke excitatory waves in single unit recordings from this region (Porter et al., 1969). Again, in monkeys detrusor muscle contractions, induced by instilling small amounts of water into the bladder, were inhibited by stimulation of the globus pallidus. Hence functional imbalance of the basal ganglia may underlie the bladder disturbances seen in Parkinsonian patients.

The supersensitivity to L-noradrenaline in patients with paralysis agitans implies a reduction in impulse traffic at sympathetic nerve terminals. It must be due to a reduction in descending vasoregulatory traffic from supraspinal centres not directly concerned in the mediation of circulatory reflexes, since these are intact. This would account also for the lower resting blood pressure in these patients when compared with control subjects and for the reduced renin levels and aldosterone secretion rates reported in Parkinsonian patients (Barbeau et al., 1970) which may represent reduced sympathetic activity in renal nerves. Furthermore, there is an overall reduction in noradrenaline formation in patients with paralysis agitans (Goodall and Alton, 1969) which is consistent with a decreased rate of noradrenaline release from nerve terminals.

There is an analogy with animal experiments using clonidine (Catapres) which reduces sympathetic but increases parasympathetic activity (Boissier et al., 1968); supersensitivity to noradrenaline may occur with a reduction in resting blood pressure and plasma renin levels while certain cardiovascular reflexes remain intact (Schmitt et al., 1968; Onesti et al., 1971). Furthermore, there is an alteration in dopamine metabolism of the mid-brain following clonidine administration (Barbeau et al., 1970) and also in Parkinsonism (Carlsson and Lindqvist, 1963; Hornykiewicz, 1966). The pathological lesions found in the thalamus, corpus striatum, hypothalmic nuclei, and brain-stem reticular formation in paralysis agitans (Foix and Nicolesco, 1925) could therefore account for both the somatic and the autonomic disturbance in this condition.

The autonomic disturbance in patients with Parkinsonism may be of two types. Whereas we have found a widespread interruption of autonomic reflexes in patients with the ShyDrager syndrome, in those with paralysis agitans the defect is more subtle and involves the set of the autonomic nervous system.

We wish to thank Dr. Michael Kremer for allowing us to study patients under his care and for his encouragement and advice throughout this work. We thank also Dr. J. D. H. Slater and Dr. C. J. Earl for allowing us to study patients under their care; Dr. Mark Jackson for his help with the intra-arterial pressure recordings and digital plethysmography; the department of radiology at the Middlesex Hospital for undertaking the micturating cinecystography; and the house physicians in the department of neurology for their help.

\section{References}

Bannister, R., Ardill, L., and Fentem, P. (1967). Brain, 90, 725 Barany, F. R., and Cooper, E. G. (1956). Clinical Science, 15, 533. Barbeau, A., Gillo-Joffroy, L., and Brossard, Y. (1970). In L-Dopa and Parkinsonism, ed. A. Barbeau and F. H. McDowell, p. 286. Philadelphia, Davis.

Barcroft, H., Brod, J., Hejl, Z., Hirsjarvi, E. A., and Kitchin, A. H. (1960). Clinical Science, 19, 577 .

Berliner, K. (1940). Archives of Internal Medicine, 65, 896.

Boissier, J. R., Giudicelli, J. F., Fichelle, J., Schmitt, H., and Schmitt, H. (1968). European fournal of Pharmacology, 2, 333.

Bolton, B., Carmichael, E. A., and Stürup, G. (1936). Fournal of Physiology, 86,83 .

Calne, D. B., Brennan, J., Spiers, A. S. D., and Stern, G. M. (1970) British Medical fournal, 1, 474

Carlsson, A., and Lindqvist, M. (1963). Acta Pharmacologica et Toxicologica, 20,140 .

Chokroverty, S., Barron, K. D., Katz, F. H., Del Greco, F., and Sharp. J. T. (1969). Brain, 92, 743

Coon, J. M., and Rothman, S. (1941). Fournal of Pharmacology and Experimental Therapeutics, $73,1$.

Cotzias, G. C., Papavasiliou, P. S., Gellene, R., Aronson, R. B., and Mena, I (1969). In Third Symposium on Parkinson's Disease, ed. F. J. Gillingham and I. M. C. Donaldson, p. 78. Edinburgh, Livingstone.

Finnerty, F. A., Tuckman, J., and Hajiar, G. C. (1959). Circulation Research. $1,565$.

Foix, C., and Nicolesco, J. (1925). Les noyaux gris centraux et la region mesencephalo-sous-optique. Paris, Masson.

Gilliatt, R. W. (1948). Fournal of Physiology, 107, 76.

Gilliatt, R. W., Guttmann, L., and Whitteridge, D. (1948). Fournal of Physiology, 107, 67.

Goldherg, My 'Pines, K. L., Baldwin, E. de F., Greene, D. G., and Roh, G. E. (1948). American fournal of Medicine, 5, 792.

Goodall, M., and Alton, H. (1969). Fournal of Clinical Investigation, 48, 2300 Goodall, McC., Harlan, W. R., and Alton, H. (1968). Circulation, 38, 592, Graham, J. G., and Oppenheimer, D. R. (1969). Fournal of Neurology, Neurosurgery and Psychiatry, 32, 28.

Greenfield, J. G. (1955). In Fames Parkinson (1755-1824), ed. M. Critchley. p. 219. London, Macmillan.

Gross, M. (1970a). Quarterly fournal of Medicine, 39, 485

Gross, M. (1970b). Clinical Science, 38, 491.

Guttmann, L. (1940). Fournal of Neurology and Psychiatry, 3, 197.

Hickler, R. B., Wells, R. E., jun., Tyler, H. R., and Hamlin, J. T. (1959a). American fournal of Medicine, 26,410.

Hickler, R. B., Hamlin, J. T., and Wells, R. E., jun. (1959b). Circulation, 20, 422 .

Hornykiewicz, O. (1966). Pharmacological Reviews, 18, 925.

Hughes, R. C., Cartlidge, N. E. F., and Millac, P. (1970). Fournal of Neurology, Neurosurgery and Psychiatry, 33, 363.
ond

Jager, W. A. (1970). Archives of Neurology, 23, 528. and Psychiatry, 23, 283 .
. A., and Bethlem, 
Janowitz, H. D., and Grossman, M. I. (1950). Fournal of Investigative Dermatology, 14, 453.

Johnson, R. H., Lee, G. de J., Oppenheimer, D. R., and Spalding, J. M. K. (1966). Quarterly fournal of Medicine, 35, 276.

Johnson, R. H., Smith, A. C., Spalding, J. M. K., and Wollner, L. (1965). Lancet, 1, 731 .

Lewy, F. W. (1923). Die Lehre vom Tonus und der Bewegung. Berlin, Springer. Luft, R., and von Euler, U. S. (1953). Fournal of Clinical Investigation, 32.

McDowell, F. H. (1970). In L-Dopa and Parkinsonism, ed. A. Barbeau and F. H. McDowell, p. 263. Philadelphia, Davis.

Martin, J. B., Travis, R. H., and Noort, S. van den (1968). Archives of Neurology, 19, 163

Murnaghan, G. F. (1961). British Fournal of Urology, 33, 403.

Onesti, G., Schwarz, A. B., Kim, K. E., Paz-Martinez, V., and Schwarz, C. (1971). Circulation Research, 28, Suppl. 2, p. 53.

Parkinson, J. (1817). An Essay on the Shaking Palsy. London. Reprinted in Fames Parkinson (1755-1824), ed. M. Critchley, London, Macmillan.

Pickering, G. W. (1955). High Blooa Pressure. London, Churchill.

Porter, R. W. Bors, E., and Hyman, W. (1969). In Third Symposium on

Parkinson's Disease, ed. F. J. Gillingham and I. M. C. Donaldson, p. 124. Edinburgh, Livingstone.
Reid, J. L., Calne, D. B., George, C. F., and Vakil, S. D. (1971). Clinical Science, 40, 6P.

Schmitt, H., Schmitt, H., Boissier, J. R., Giudicelli, J. P., and Fichelle, J. (1968). European fournal of Pharmacology, 2, 340.

Schwarz, G. A. (1967). Archives of Neurology, 16, 123. harpey-Schafer, E. P. (1965). In Handbook of Physiology, vol. 3, Section 2, Circulation, ed. W. F. Hamilton and P. Dow. p. 1875

Sharpey-Schafer, E. P., and Taylor, P. J. (1960). Lancet, 1, 559.

Shy, G. M., and Drager, G. A. (1960). Archives of Neurology, 2, 511

Spiegel, E. A., Wycis, H. T., Schor, S., Schwartz, H. A., and Fabioni, F. R. (1969). In Third Symposium on Parkinson's Disease, ed. F. J. Gillingham and I. M. C. Donaldson, p. 200. Edinburgh, Livingstone.

Stead, E. A., jun., and Ebert, R. V. (1941). Archives of Internal Medicine, $67,546$.

Thomas, J. E., and Schirger, A. (1970). Archives of Neurology, 22, 289.

Vanderhaeghen, J. J., Perier, O., and Sternon, J. E. (1970). Archives of Neurology, 22, 207.

Verel, D. (1951). British Heart fournal, 13, 61.

Yahr, M. D., Duvoisin, R. C., Hoehn, M. M., Schear, M. J., and Barrett, R. E. (1968). Transactions of the American Neurological Association, 93, 56.

\title{
Endogenous Creatinine Clearance as a Clinical Measure of Glomerular Filtration Rate*
}

\author{
WILLIAM M. BENNETT, GEORGE A. PORTER
}

British Medical fournal, 1971, 4, 84-86

\section{Summary}

Endogenous creatinine clearance was assessed by inulin in 91 simultaneous studies in 41 patients and proved an accurate measurement of glomerular filtration rate. For filtration rates $<20 \mathrm{ml} / \mathrm{min}$ the creatinine clearance may slightly overestimate the glomerular filtration rate. Successive determinations of filtration rate by either method may vary by $20 \%$ even though the methods agree with each other. Glomerular filtration rate itself is variable, and in its clinical usage this should be recognized.

\section{Introduction}

A report by Kim et al. (1969) has questioned again the validity of the endogenous creatinine clearance for the clinical estimation of the glomerular filtration rate. Based on 308 simultaneous determinations of inulin and creatinine clearances these authors reported that the creatinine clearance overestimated the filtration rate as measured by inulin in both normal patients and those with kidney disease. Not only did the ratio of creatinine clearance to inulin clearance increase as filtration rate declined but they also found a ratio greater than one in the normal range. If these findings are valid, then the usefulness of creatinine clearance as a screening test of renal function would be limited.

Our experience is at variance with these observations. In our experience inulin clearance and creatinine clearance showed close correlation. However, the filtration rate itself was variable over both the short term and the long term by either measuring technique. We feel that this point needs emphasis, since thera-

* Supported by PHS-CV Program Project HE 06336-10 CRC 5 MOI RR 334-05.

Renology Section, University of Oregon Medical School, Portland, Oregon, U.S.A.

WILLIAM M. BENNETT, M.D., Assistant Professor of Medicine GEORGE A. PORTER, M.D., Associate Professor of Medicine peutic decisions must take into account spontaneous variations in filtration rate or run the risk of being erroneous.

\section{Methods}

Ninety-one simultaneous inulin and creatinine clearances were performed in 41 patients. Six patients were normal volunteers, 19 were undergoing cardiac catheterization under local anaesthesia but had no known renal disease, and 16 had a variety of renal diseases. There were 16 men and 25 women ranging in age from 18 to 69 .

Priming doses of $10 \%$ inulin of $50 \mathrm{mg} / \mathrm{kg}$ were given followed by a constant infusion of $2 \mathrm{ml} / \mathrm{min}$ with an infusion pump (Porter et al., 1966). Forty-five minutes were allowed for equilibration and no clearance was used unless plasma inulin was $25-35 \mathrm{mg} / 100$ and urine flow was at least $2 \mathrm{ml} / \mathrm{min}$. All studies were done in supine patients without water loading. Complete urine collections were insured by indwelling bladder catheterization and aspiration of the bladder followed by two air rinses after each 15-minute clearance period. Inulin was determined tiy the method of Roe et al. (1949) and endogenous creatinine by a total chromogen method as described by Haugen (1953). After equilibration three 15-minute clearances were averaged. Duplicate samples of blood and urine were processed for inulin and creatinine. Inulin duplicates varied by $1 \cdot 7 \pm 3 \%$ for plasma and $2 \cdot 2 \pm 2 \%$ for urine, while creatinine varied by $0.4 \pm 1.3 \%$ for serum and $0.2 \pm 0.3 \%$ for urine.

Thirty-nine patients had successive clearance studies repeated one hour after the initial study while still in a steady state of plasma inulin and urine flow. Clearance rates were computed by the standard formula (Homer Smith, 1956) but correction to a standard body surface area was performed only in the 19 cardiac catheterization patients.

\section{Results}

Fig. 1 is a correlation of endogenous creatinine clearance $\left(\mathrm{C}_{\mathrm{cr}}\right)$ to inulin clearance $\left(\mathrm{C}_{\mathrm{in}}\right)$ for the entire series, while Fig. 2 depicts the U/P ratios. The relationship is essentially linear. The correlation is striking, with a mean ratio of $\mathrm{C}_{\mathrm{cr}} / \mathrm{C}_{\text {in }}$ of $0.95 \pm 0.03$. When the patient results were divided into those 